Environmental Research Journal 4 (1): 140-144, 2010

ISSN: 1994-5396

(C) Medwell Journals, 2010

\title{
Application of Geo-Information for Evaluation of Land Use Change: A Case Study of Federal Capital Territory-Abuja
}

\author{
Marcus A. Idoko and Francis E. Bisong \\ Department of Geography and Regional Planning, University of Calabar, Calabar C.R. State, Nigeria
}

\begin{abstract}
The dearth of data for research in Nigeria has masked the clear understanding of the land cover alteration processes due to land use change and their consequences. This research is focused on the use of geo-information to monitor landscape transformation in space and time. Satellite imageries of two epochs, covering Abuja Federal Capital Territory (FCT) were acquired. Landsat TM and Nigeria Sat were enhanced to improve visualization in ILWIS. The imageries were characterized into five classes (Vegetation, Built-up, Rock-outcrop, Waterbody and Farmland). The classification was done with maximum likelihood algorithm, which resulted in classes of each land use. The two classified images were compared to identify change between 1987 and 2004. A spatio-temporal change in land use type was obtained in quantitative terms. Vegetation covers in 1987 reduced by $85.22 \%$ in 2004, while built up increased by $21.99 \%$, in 2004. Farmland cover increased by $0.14 \%$ during the period. This methodology offers access to quality digital image data, which improves the poor data base situation in Nigeria for better appreciation and knowledge of the interactions between man and his environment to leverage informed decisions.
\end{abstract}

Key words: Change detection, land cover, land use, geo-reference, resample, pixel size, resolution, spectral band, spatio-temporal

\section{INTRODUCTION}

Over the years man has exploited the land he inhabits to a degree unparalleled by any other species. An aerospace view of the landscape attests to the extent to which man has modified the environment to suite his purposes. Land is one of the non-renewable resources in high demand, yet it represents only about $29 \%$ of the earth's surface (Brown and Pijanowsk, 2000). Man however, subjects the land to various development activities such as Agriculture, urbanization, mining and other exploitative processes that alters land cover and the general environment rapidly. Consequently the geography of the earth is in constant and rapid change.

As human beings continue to alter the environment on a vast scale, geographers and cartographers face significant challenges in keeping track with the eco-trend and updating/production of maps that reflect these changes. Furthermore, efforts by scientists, planners and policy makers to fully appreciate environmental challenges due to dearth of data and poor geo-database undermined. Fortunately, new synergistic technologies, such as remote-sensing satellites, GIS packages and applications are making their task easier (ILWIS 3.0 Academics, 2001). The introduction of remote sensing techniques and computer-based Geographic Information
Systems (GIS) has revolutionized land-use mapping and made it possible to gather large amounts of information quickly (Lucas and Gerrit, 2001). This technology is deployed in this work through the application of GIS to study impact of land use change on the Federal Capital Territory using satellite imageries of 1987 and 2004.

This research attempts to utilize geo-information, particularly image data to evaluate impact of land use change occasioned by the massive human influx into Abuja Federal capital attendant high demand for land. It is a research intended to create a geospatial model that could be used by geographers, ecologist and planners to appreciate the environmental trend and detect change(s) that may be useful for scheming sustainable appropriation of resources (Foster, 1999).

Finally, this research is aimed at sensitising scholars and scientists towards use of geo-information to leverage research efforts in the face of apparent lack of quality data in sub-Saharan Africa.

Study area: The study area under investigation is Abuja FCT Federal capital territory, it lies between the latitude $9,00^{\circ}$ North, longitude $6,00^{\circ}$ East and latitude $14,08^{\circ}$ North, longitude $7,58^{\circ}$ East. It has a total area of $\left(713 \mathrm{~km}^{2}\right.$ i.e., $71.300 \mathrm{ha}$ ) with an estimated population of 1.8 millions (Fig. 1).

Corresponding Author: Marcus A. Idoko, Department of Geography and Regional Planning, University of Calabar, Calabar C.R. State, Nigeria 


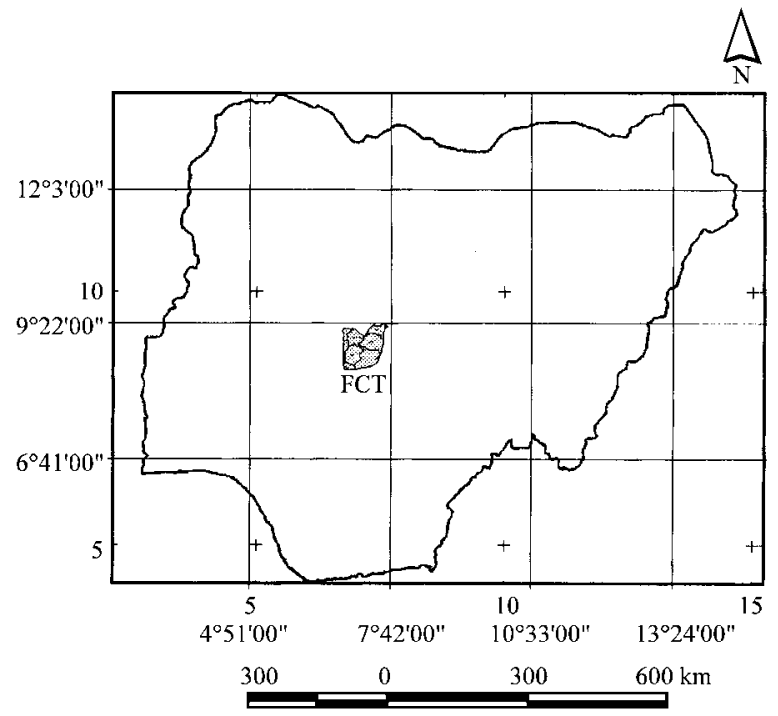

Fig. 1: Study area

When, it was decided to move the national capital from Lagos in 1976, a capital territory was chosen for a new city, located near the centre of the country.

Construction broke ground in the late 1970s, but due to economic and political instability, the city in its initial stages was not completed until the late 1980s. Abuja officially became Nigeria's capital on 12th December 1991.

Ecological zone: FCT falls within the savannah zone vegetation of West African sub-region.

It experiences three weather conditions annually. These include a warm season with the temperature of day time reaching $28-30^{\circ} \mathrm{C}$, which some times get to as high as $40^{\circ} \mathrm{C}$ and night time temperatures of about $22-23^{\circ} \mathrm{C}$, which can dip to $15^{\circ} \mathrm{C}$, resulting in chilly evenings (AbujaWikipidia (2007) the free encyclopaedia page 2, 5/30,; http:wiki/Abuja5/30/2007).

Humid rainy season having annual rainfall is in the range of $1100-1600 \mathrm{~mm}$. The dry season is characterized by blistering dry weather. In between the two seasons (i.e., rainy and dry seasons), there is a brief interlude of harmattan underscored by the North East Trade Wind, with the main feature of dust haze, intensified coldness and dryness (http://wiki/Abuja 5/30/2007).

\section{MATERIALS AND METHODS}

Two sets of satellite imageries landsat TM, 1987 and Nigersat, 2004 covering the study area were acquired. The two imageries were multi spectral images (RGB) with spatial resolutions of 28.2 and $32 \mathrm{~m}$, respectively.

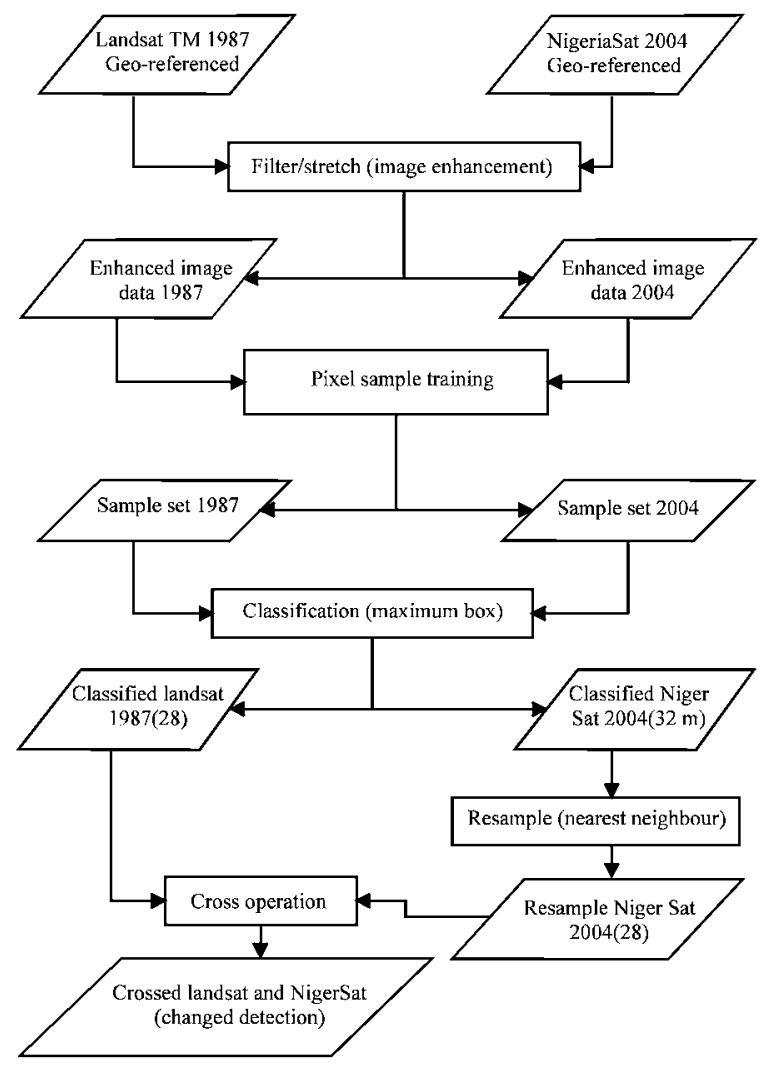

Fig. 2: Flow chart of methodology

Image enhancement and classification: GIS application software, ILWIS, was deployed for image visual enhancement and classification.

Image visual enhancement: The imageries were filtered and stretched to enhance visualization. The Nigersat of lower resolution was resampled using nearest neighbour algorithm to the Landsat image resolution enable cross and overlay operations.

Image classification: The visually enhanced imageries were classified based on sample set created according to training pixel. The classification was done using false colour composite image with class domain of five classes to generate, Built up (cyan), Vegetation (Red), Water body (black), Farmland (white) and Rock outcrop (ash).

The classification was carried based on the five classes based on assigned value to each pixel, which is referred to as pixel training. Each pixel represents one of the defined classes, which are represented by colours in the created domain. The imageries were classified using maximum likelihood algorithm. The classified imageries were converted to represent the classes with true colour from the class domain linked to representation object in ILWIS environment. 
Cross operation: The two classified map were crossed using ILWIS GIS operation to produce changed detection map and table. A column management operation was carried out to create a new column where changed and non-changed scenarios between 1987 and 2004 were identified. The column was further sliced into five classes and attribute map was finally created and named changed detection map.

The stepwise procedure used for analysing image data that resulted in the classified imageries and the cross operation that yielded a change detection map (Fig. 2).

\section{RESULTS}

Classified Image representation of Land use change of Federal Capital Territory Abuja between 1987 and 2004 shown in Fig. 3 and 4. The greenish area coverage is more compared to pink colour area. The blue is concentrated in the North East corner of the image map.

The state of land use coverage of Federal capital territory in 1987, which was generated from the supervised image classification of Land sat TM of $28.5 \mathrm{~m}$ resolution.

The state of land use coverage of Federal capital territory in 2004, generated from supervised image classification of Nigeria Sat $32 \mathrm{~m}$ resolution. This shows an increased in pink and ash colour area coverage as against greenish colour area. The Blue colour area is wide spread but not concentrated in particular area.

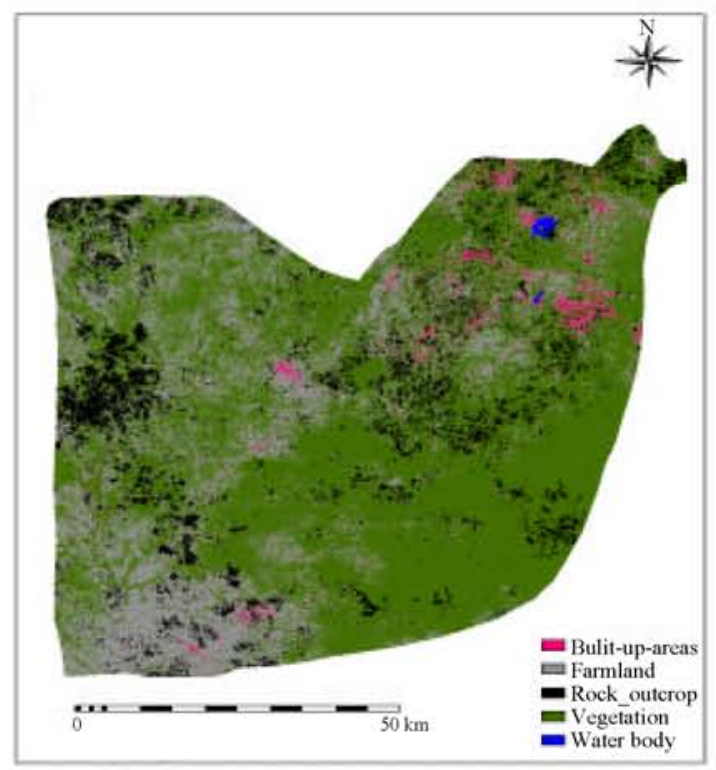

Fig. 3: Land use/cover map of Abuja Capital Territory in 1987
Changed detection obtained from crossed operation between landsat TM, Fig. 3 and Nigeria sat, Fig. 4 is shown below in Fig. 5. Built up area is shown in cyan colour. White representation replaces blue colour areas

Graphic representation of land use coverage of 1987 scenario is shown in Fig. 6. The vegetation bar in 1987 is

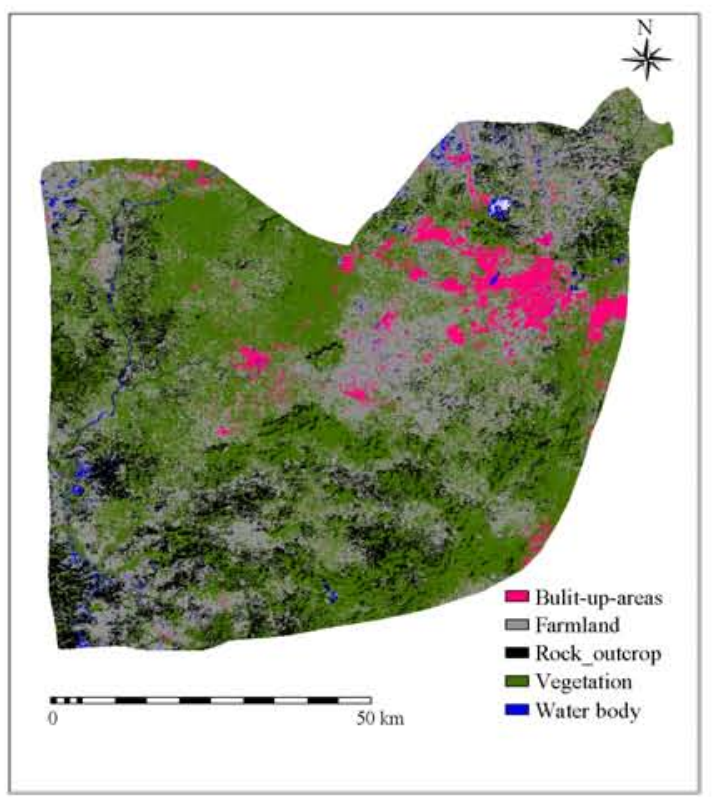

Fig. 4: Land use/cover map of Abuja Capital Territory in 2004

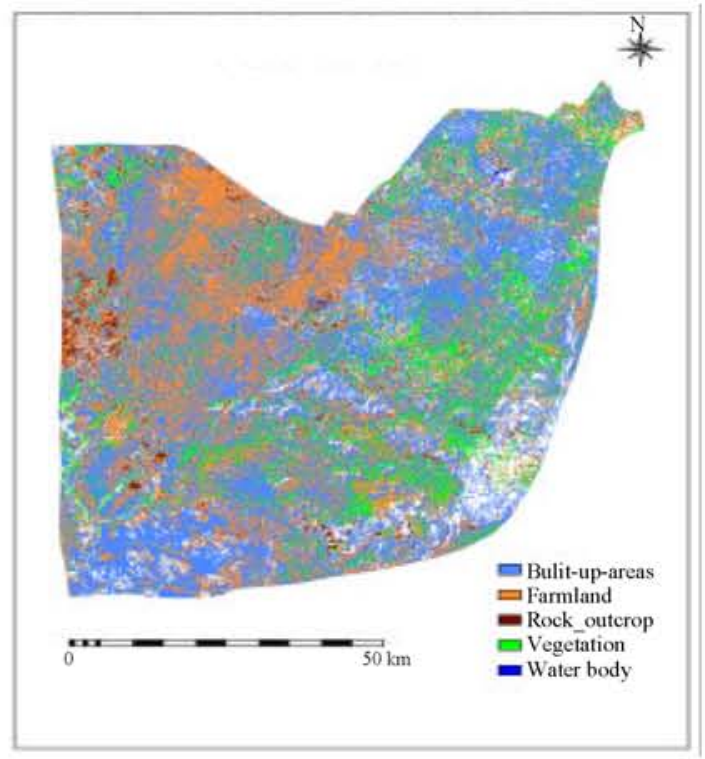

Fig. 5: Changed detection between 1987 and 2004 in Abuja Capital Territory 


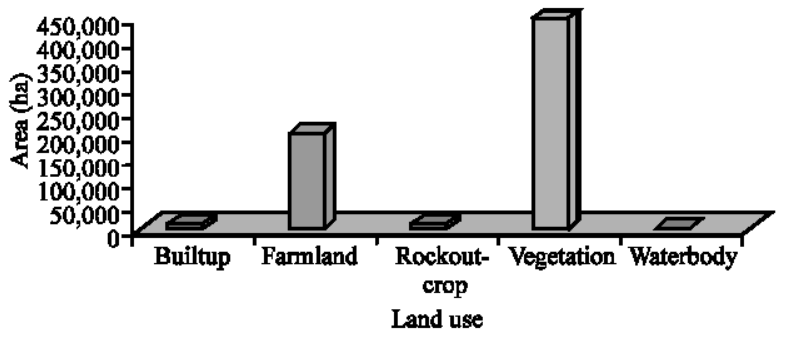

Fig. 6: Land use spatial coverage 1987

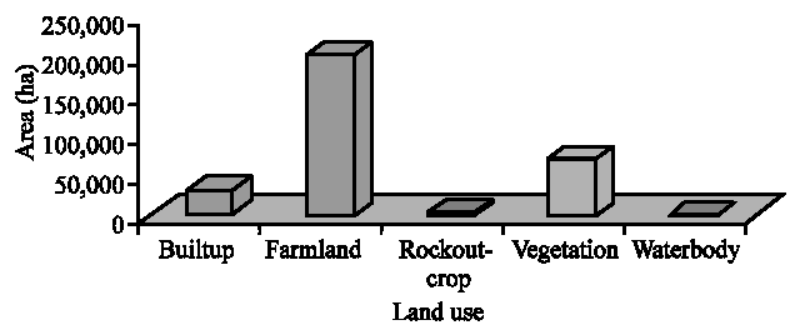

Fig. 7: Spatial land use spatial coverage (change detection) in 2004

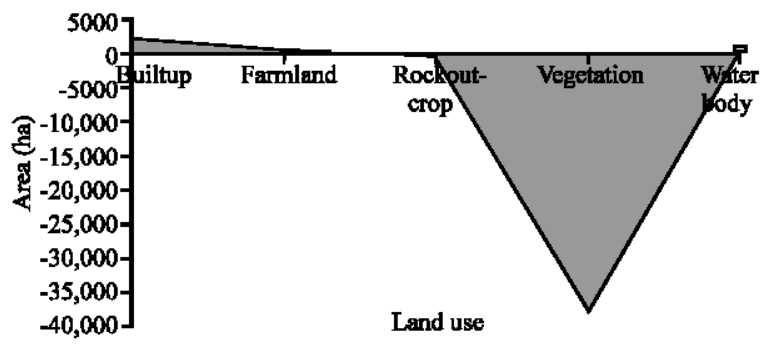

Fig. 8: Change in land use between 1987 and 2004

higher than other land uses bar as shown in the bar chart below. Farm land bar is next to vegetation followed by built up the rest.

The bar chart representation of land use coverage in 2004 scenario is shown in Fig. 7. The farmland and built up bar are higher compared to vegetation bar in Fig. 6 .

Graphical representation of change in land use coverage between 1987 and 2004 shown Fig. 8. A clear difference in change is shown where vegetation has decreased significantly compared slight increase in built up and farmland.

\section{DISCUSSION}

It is clearly indicated by the results of the classification that in 1987 , the vegetation cover in the study area occupied 483890.6 ha that is about $65.99397 \%$ of the total area of Abuja FCT. While, the built up areas merely covered 6852.547 ha, which represents $0.934564 \%$ of the total areas of the study area (Fig. 3 and 4). The temporal change of vegetation cover and built up area between 1987 and 2004 was quite significant. Vegetation of course, coverage reduced from 445507-71488 ha. Representing $17.35 \%$ reduction in vegetation cover, while built up area increased from 9754-31160 ha, representing $3.3 \%$ increase in built up coverage. Farm land also increased significantly from 199208-202091 ha 8.83\% change (Fig. 5 and 6).

It is important to note the two classified imageries were of different pixel sizes (resolutions) of $28.5 \mathrm{~m}$ for Land sat and $32.0 \mathrm{~m}$ for Nigeria Sat. The difference in pixel sizes introduced significant error. This error was minimized by carrying out re-sampling and cross operation to normalize the difference in pixel to enable cross operation.

The cross operation produced a more reliable land use coverage in 2004. This map, Fig. 5, is referred to as change detection map. It is clear that land use coverage change between 1987 and 2004 was positive for human activities (Farmland and built up covers) and negative for natural coverage (vegetation and rock outcrops). This development points to that truth that human activities constitute one of the major factors that determine state of the environment and land degradation in particular.

Careful observation of the 1987 situation in Fig. 3, water body presence is concentrated in the dam located at the north east corner of the classified image. The 2004 image situation suggests drastic reduction in the water available in the dam, which could have been as a result of siltation or overstretched by increased demand due to rising population. However, there is an increase in the overland flow in Fig. 4. This is an indication of increase in impervious surface due to increased built up and agriculture land uses. The land use change altered the structure and texture of the soil, hence undermining water infiltration/percolation processes with resultant rising temperature, increase in runoff and possible inundation of the study area after rainstorm.

Graph representations in Fig. 6-8 were created from the spectral-graph of the Fig. 3, 4 and 6, respectively. Figure 8 shows that man made features such as built up and farmland increased while natural features including vegetation, rock out crop and water body decreased. This is indicative of dominance of man in the study area.

Limitation: Remote sensing exercise without ground truth cannot be complete. The field survey should have increased the accuracy of the research. There would have been confusion matrix output, i.e. comparison of image interpretation and field observation. Unfortunately this exercise was not carried out in this research. 


\section{CONCLUSION}

This research demonstrated the capability of geoinformatics techniques to capture data covering large area extent over a long time frame. In addition, the technique integrated and analysed the large and complex data generated from digital numbers in pixels that are associated with the raster image data to produce useful information on characteristics of the landscape due to impacts of human activities.

It is apparent from the result of the study that human activities are significant drivers that determines the wholesomeness or otherwise of the environment. The mass movement of people to FCT Abuja and rapid land use change can lead to some environmental disasters such as flooding and heat wave in the future if nothing to done to address the unprecedented land cover change in the study area. This study provides a model for monitoring environment with a view to preventing undesirable environmental occurrences however, it is expedient to ensure that the quality of data input, otherwise the model might be faulty and may lead wrong decision making.

\section{RECOMMENDATIONS}

In the present reality of inadequate data for research activity in Nigeria, It will be necessary to recur to application of geo-information, such as optical and radar image data because they offer more reliable data and easy to use.

This source of data however, is costly for individuals and academic institutions. I will recommend complete adoption of data sharing in line with Open Geospatial Consortium (OGC) resolution. It will be appreciated if government institutions that are privileged to possess both digital and hardcopy image to share with academic and research institutions for non profit research purposes.

\section{REFERENCES}

Brown, D.G. and D.J. Pijanowsk, 2000. J. Environ. Change, 4: $247-250$.

Foster, G., 1999. Development residential uses or agricultural abandonement leads to regrowth of forests. African Journal of Agriclture Research.

ILWIS 3.0 Academics, 2001. ITC, Enschede. The Netherlands.

Lucas, L.F. and C.H. Gerrit, 2001. Introduction to Remote Sensing ITC, Enshede, The Netherlands.

Wikipidia, 2007. FCTA buja_Development. http://enwikipidia.org/wiki/Abuja5/30/2007. 